\title{
Relação dos indicadores de desigualdade social na distribuição espacial dos casos de Zika Vírus
}

\author{
Relationship between social inequality indicators and the spatial \\ distribution of Zika Virus cases
}

Lizailma Silva Cunha (https://orcid.org/0000-0003-4816-3493) ${ }^{1}$

Wilton Rodrigues Medeiros (https://orcid.org/0000-0002-9096-8108) ${ }^{2}$

Francisco Assis Vieira Lima Junior (https://orcid.org/0000-0001-8877-5406) ${ }^{3}$

Silvana Alves Pereira (https://orcid.org/0000-0002-6226-2837) ${ }^{1}$
${ }^{1}$ Programa de PósGraduação em Saúde

Coletiva, Universidade Federal do Rio Grande do Norte (UFRN). R. Teodorico Bezerra s/n, Campus Santa Cruz. 59200-000 Santa Cruz RN Brasil.

apsilvana@gmail.com ${ }^{2}$ Hospital Universitário Ana Bezerra, UFRN. Santa Cruz RN Brasil.

${ }^{3}$ Centro Universitário do Rio Grande do Norte. Natal RN Brasil.

\begin{abstract}
The aim of this article was to analyze the possible relationship between social inequality indicators and the spatial distribution of ZIKV cases in a state in Northeastern Brazil in 2015-16. This is an ecological study with the data of notified ZIKV cases and the sociodemographic indicators of Rio Grande do Norte state (RN), based on information from the State Public Health Department (SESAP-RN) and DATASUS. The data were analyzed in Terraview version 4.2.2, Geoda version 1.12 and IBM SPSS Statistics 21. Both the average incidence rate (AIR) of ZIKV cases in 2015-16 (Moran $=0.139 ; p=0.03$ ) and the AIR of violence (Moran $=0.295 ; p=0.02$ ), average household income (Moran $=0.344 ; p=0.01$ ) and unemployment rate (Moran $=0.231 ; p=0.01$ ) exhibited a geographic spatial distribution pattern. In multiple linear regression analysis, the variables AIR of violence and average household income explained $55 \%$ of the variation in the AIR of ZIKV in 2015-16 (adjusted R2 = 0.55). Municipalities with more notifications of violence and higher average income, such as the state capital, reported a higher number of ZIKV cases, possibly due to better organization, greater awareness of socioenvironmental problems and easier access to health services.
\end{abstract}

Key words Zika virus, Violence, Health indicators, Microcephaly, Epidemiology
Resumo $O$ objetivo deste artigo é analisar a possivel relação de indicadores que refletem a desigualdade social sobre a distribuição espacial dos casos de Zika vírus (ZIKV) em um estado do Nordeste brasileiro no Biênio 2015-2016. Estudo ecológico com dados das notificações de casos de ZIKV e indicadores sociodemográficos do estado do Rio Grande do Norte (RN) calculados a partir de dados da Secretaria de Estado de Saúde Pública do RN (SESAP-RN) e DATASUS. Os dados foram analisados no Terraview versão 4.2.2, no GeoDa versão 1.12 e no IBM SPSS Statistics 21. Observou-se que tanto a Taxa Média de Incidência (TMI) de casos de ZIKV no biênio de 2015-2016 (Moran $=0,139 ; p=0,03$ ) quanto a TMI de violência (Moran $=0,295 ; p=0,02)$, renda média domiciliar (Moran=0,344; $p=0,01$ ) e taxa de desemprego (Moran $=0,231 ; p=0,01$ ) obedeceram um padrão geográfico de distribuição espacial. Na análise de regressão linear múltipla as variáveis TMI de violência e renda domiciliar média explicaram 55\% da variação da TMI de ZIKV no biênio 2015$2016\left(R^{2}\right.$ ajustado $\left.=0,55\right)$. Municípios com mais notificaçôes de violência e renda média favorável, como a capital, detêm maiores TMI de casos de ZIKV, fenômeno mediado possivelmente pela melhor organização, maior clareza aos problemas socioambientais e ainda, melhor acesso aos serviços de saúde.

Palavras-chave Zika vírus, Violência, Indicadores de saúde, Microcefalia, Epidemiologia 


\section{Introdução}

O vírus Zika (ZIKV) trata-se de uma arbovirose, doença ocasionada por um grupo de vírus ecologicamente denominado arbovírus ${ }^{1}$, neste caso especificamente, um vírus do gênero Flavivirus, que é transmitido por mosquito do gênero Aedes, sendo seus principais vetores o Aedes aegypti e Aedes albopictus. Existindo ainda a possibilidade de transmissão sanguínea e neonatal, apesar de não se conhecer o real papel dessas vias de transmissão na propagação desta infecção ${ }^{2}$.

O ZIKV apesar de ser considerada uma enfermidade aguda de manifestações brandas e autolimitadas, tornou-se um problema de saúde pública mundial em decorrência de seus impactos na saúde, uma vez comprovada sua associação com uma série de distúrbios neurológicos, a exemplo da síndrome de Guillain-Barré (SGB) e malformações congênitas, em que se destaca a microcefalia ${ }^{2}$.

No Brasil, esse vírus foi introduzido em 2015 com a confirmação autóctone na Bahia e em seguida no Rio Grande do Norte $(\mathrm{RN})^{3,4}$. Sendo inicialmente detectado no $\mathrm{RN}$ no município de Natal e posteriormente, no município de São Gonçalo do Amarante ${ }^{3,5}$, com 8.743 notificações de casos suspeitos e 113 casos confirmados. No ano de 2016, entre o período de janeiro a novembro, registrou-se 5.971 notificações de casos suspeitos e 205 confirmados $^{6}$.

Uma das hipóteses para justificar essa disseminação foi o envolvimento de determinantes ambientais e socioeconômicos do território, sob a premissa de que este conhecimento é fundamental na fomentação de estratégias de planejamento e gestão em saúde para o enfrentamento desta enfermidade ${ }^{7,8}$.

Algumas pesquisas sugerem haver correlação entre determinantes sociais de saúde como etnia, escolaridade, renda e aumento na incidência de ZIKV e suas consequências, a exemplo da microcefalia $^{9-11}$.

As desigualdades sociais em saúde referemse àquelas diferenças percebíveis e mensuráveis existentes quer sejam relacionadas às diferenças no acesso aos serviços de prevenção, cura ou reabilitação da saúde. E estão intimamente relacionadas ao meio social em que os indivíduos estão inseridos, sendo profundamente influenciado pela condição social das pessoas bem como pelo local onde residem ${ }^{12,13}$.

A avaliação das desigualdades sociais sob o contexto das epidemias de arboviroses toma ainda mais base à medida que tanto o Aedes aegypti quanto Aedes albopictus, principais vetores de arbovírus no país, ampliaram sua faixa geográfica e passaram a estar cada vez mais associado ao meio urbano, sobretudo em cidades de países em desenvolvimento, onde o processo de urbanização tem se dado de forma acelerada e não planejada, o que tem levado a fragilidades socioespaciais ${ }^{14}$.

À exemplo de fragilidade socioespaciais com impactos sobre a saúde pública tem-se a desigualdade estrutural, onde de um lado se encontra bairros luxuosos com infraestrutura adequada, com serviços públicos atuantes e de outro, bairros precários, com má distribuição de renda, inexistência de serviços básicos como rede de esgoto, coleta de lixo e abastecimento de água, ao que se soma ainda o permanente estado de insegurança físico-ambiental ${ }^{15,16}$.

De fato, o processo de saúde-doença está condicionado a uma complexidade de fatores que estão relacionados às condições de vida dos indivíduos, sendo essas características identificadas como Determinantes Sociais da Saúde (DSS), os quais correspondem aos fatores socioeconômicos, culturais, éticos/raciais, psicológicos e comportamentais e que em conjunto com as situações de saúde, permite identificar onde e como devem ser realizadas as intervenções em saúde pública, de forma a proporcionar um maior impacto com o objetivo de reduzir as iniquidades ${ }^{1,17,18}$.

No entanto, mesmo já se tendo comprovado as relações de impacto entre os determinantes sociais às doenças, ainda se é negligenciado o problema da determinação social no aspecto tecnológico e biomédico ${ }^{2}$. A exemplo dessa abordagem tem-se a epidemia do ZIKV, revelando como a agenda da saúde globalmente negligencia a diversidade de experiências e as múltiplas reproduções de desigualdade, dificultando a compreensão plena da saúde e da doença ${ }^{7}$.

Diante desta perspectiva este trabalho tem por objetivo analisar a relação entre indicadores de desigualdade social e distribuição espacial dos casos de ZIKV em um estado do Nordeste brasileiro no biênio de 2015-2016.

\section{Metodologia}

\section{Desenho, local e população de estudo}

Trata-se de um estudo ecológico, cuja unidade de estudo é os municípios do estado do Rio Grande do Norte (RN). Este estado encontra-se situado na Região Nordeste do Brasil e tem por limites o Oceano Atlântico a norte e a leste, o es- 
tado da Paraíba a Sul e o Ceará a Oeste, sendo dividido em 167 municípios, possuindo uma área total de $52.811,110 \mathrm{Km}^{2}$, o que equivale a $3,42 \%$ da área do Nordeste e a $0,62 \%$ da superfície do Brasil $^{19}$.

Segundo IBGE $^{19}$, o estado do RN é dividido por quatro mesorregiões geográficas, agrupadas segundo critérios sociais e econômicos similares: litoral potiguar (formado por 25 municípios), agreste potiguar (formado por 43 municípios), central potiguar (formado por 37 municípios), oeste potiguar (formado por 62 municípios).

\section{Coleta de dados e variáveis estudadas}

Com base na premissa da influência dos fatores socioambientais sob a incidência dos casos de ZIKV, este estudo buscou analisar a relação dos indicadores de desigualdade social na distribuição espacial dos casos de ZIKV no estado do RN no biênio de 2015-2016. Inicialmente coletaram-se os números de casos de ZIKV nos anos de 2015 e 2016 junto à Secretaria de Estado de Saúde Pública do RN (SESAP-RN), por meio do Sistema de Informação de Agravos de Notificação (SINAN), e posteriormente realizou-se a somatória do número de casos dos anos de 2015 e 2016 divididos pelo total da população nestes referidos anos em razão a cada 10.000 habitantes ao que se intitulou por Taxa Média de Incidência (TMI) de ZIKV no biênio 2015-2016.

As variáveis socioambientais testadas foram: 1) TMI de violência em 2014: Que corresponde a incidência de violência no ano de 2014 dividida pelo total da população neste referido ano em razão a cada 10.000 habitantes; 2) Renda Média Domiciliar per capta 2010: Média das rendas domiciliares per capta das pessoas residentes em determinado espaço geográfico, no ano considerado; 3 ) Taxas de Desemprego 2010: Proporção (\%) da população residente economicamente ativa de 16 anos e mais que se encontra sem trabalho no período de referência, em determinado espaço geográfico, no ano considerado; 4) Analfabetismo 2010: Proporção de analfabetos na população total; 5) Abastecimento de água 2010: Distribuição percentual da população moradora atendidas com Abastecimento de água em 2010; 6) Instalações sanitárias 2010: Distribuição percentual da população moradora atendidas com Instalações sanitárias 2010; 7) Índice de Gini 2010: Grau de desigualdade existente na distribuição de indivíduos segundo a renda domiciliar per capta; 8) Produto Interno Bruto (PIB) de 2013: Valor do PIB municipal. Os valores são apresentados em milhares de reais correntes, não sendo aplicado nenhum deflator ou fator de correção.

Estas variáveis socioambientais foram coletadas a partir da plataforma DATASUS, na aba "Informações de Saúde", restringindo à procura a aba de informações demográficas e socioeconômicas e sendo coletadas referentes ao período em que as mesmas estivessem disponíveis em períodos próximos ao ano de 2015, ano este ao qual se confirmou o surto de ZIKV no país.

No que corresponde aos aspectos éticos da pesquisa, este estudo dispensou submissão em comitê de ética, não havendo qualquer possibilidade de dano de ordem físico ou moral na perspectiva do indivíduo e das coletividades, sendo, portanto, respeitados os princípios contidos na Resolução 466/12.

\section{Análise dos dados}

A base cartográfica (shape) utilizada foi a do IBGE, obtida em seu próprio site. Inicialmente foram construídos mapas temáticos das variáveis supracitadas, fase que se constituiu na análise exploratória dos dados espaciais. Sua produção se deu utilizando o software TerraView 4.2.2, no qual, para a legenda do quantitativo da distribuição da TMI de ZIKV no biênio 2015-2016 foi dividido em cinco faixas, por meio da opção de divisão "passos iguais". Sendo escolhida a escala de cinza para a comparação visual e para a confecção da composição da legenda utilizou-se um dégradé, onde a representação do conjunto de municípios com a pior situação está em tom mais escuro.

A análise de dependência espacial foi executada utilizando-se o índice de Moran Global que estima a autocorrelação espacial, podendo variar entre -1 e +1 , além de fornecer a significância estatística do mesmo (valor de $p$ ) e que ao verificar a hipótese da dependência espacial os valores de Moran podem ser positivos (correlação direta; valores semelhantes tendem a se localizar vizinhos) ou negativos (correlação inversa; valores altos estarão cercados de valores baixos, e vice versa).

Foi analisada a presença de clusters pelo índice de Moran local (LISA), que determina a dependência dos dados em relação aos seus vizinhos. Este indicador consiste em identificar padrões de associação espacial que podem caracterizar a ocorrência de agrupamentos (ou clusters) entre os polígonos estudados. Tais dados foram apresentados através dos BoxMap (apresenta a presença de clusters sem considerar a significân- 
cia), MoranMap (apresenta os clusters com significância estatística).

Com o software GeoDa versão 1.12 (Spatial Analysis Laboratory, Universidade de Illinois, Urbana-Champaign, EUA) foi realizada a análise bivariada LISA para avaliação da correlação espacial entre a variável desfecho (TMI de ZIKV no biênio 2015-2016) e as variáveis independentes que apresentaram distribuição espacial com base na análise no Índice de Moran Global e que, portanto, atenderam aos critérios estabelecidos para a análise bivariada. Assim, pode-se visualizar a associação linear entre uma variável xk no local i, xk i e a lag espacial correspondente para a outra variável Wyi l (lkl = xk 'Wyi/n). Para tanto, foram construídos os mapas temáticos com cada par de variáveis e verificado a sua significância estatística.

A dependência espacial poderá ser direta ou inversa de acordo com o valor do Moran encontrado. $\mathrm{E}$ as relações entre os vizinhos nos clusters poderão ser dos tipos: Alto-Alto (altas TMI de ZIKV no biênio 2015-2016 e altas taxas da variável independente), Baixo-Baixo (baixas TMI de ZIKV no biênio 2015-2016 e baixas taxas da variável independente), Alto-Baixo (altas TMI de ZIKV no biênio 2015-2016 e baixas taxas da variável independente), Baixo-Alto (baixas TMI de ZIKV no biênio 2015-2016 e altas taxas da variável independente).

As variáveis independentes deste estudo que demonstraram autocorrelação na análise espacial, foram testadas pelo modelo de regressão espacial multivariada no software GeoDa versão 1.12 e o modelo que mais se enquadrou para melhor representação da relação das variáveis foi o modelo clássico de regressão linear múltipla. Para a realização desta análise de regressão utilizou-se o programa estatístico IBM SPSS Statistics 21 , ficando no modelo final as variáveis independentes que melhor predisseram a Taxa Média de incidência de ZIKV no biênio 2015-2016.

\section{Resultados}

Em relação à existência de autocorrelação espacial para a TMI de ZIKV, o Coeficiente Global de Moran foi de 0,172 e significativo para o ano de $2015(p=0,04)$, e de 0,075 e não significativo para $2016(p=0,07)$. Contudo para a TMI para o biênio de 2015-2016 foi possível verificar uma autocorrelação na distribuição destes casos, com Coeficiente Global de Moran de 0,139 e um valor $p=0,03$ (Figura 1).
Em relação à análise de dependência espacial, não se encontrou autocorrelação espacial para as variáveis de abastecimento de água (Moran = $0,001, p=0,46$ ), analfabetismo (Moran $=0,039, p$ $=0,18)$, índice de Gini (Moran $=0,049, p=0,22)$, instalações sanitárias (Moran $=0,001, p=0,46) \mathrm{e}$ Produto Interno Bruto (PIB) (Moran $=0,007, p$ $=0,42)$ e com isso esses indicadores não atenderam aos critérios estabelecidos para uma análise bivariada, e, por conseguinte não foram incluídos nas análises posteriores. Nesse sentido, serão consideradas a TMI de Violência, Renda Média Domiciliar e Taxa de Desemprego.

No mapa do RN pode-se verificar que o maior número de municípios com altas taxa média da incidência de ZIKV encontra-se localizado na mesorregião do litoral potiguar, onde se localiza a capital do estado (Figura 1c).

Em relação ao BoxMap que mostra a autocorrelação das variáveis, pode-se perceber que a mesorregião do litoral potiguar foi a que mais apresentou aglomerados do tipo alto-alto relativo à TMI de ZIKV no biênio de 2015-2016 (Figura 2a) e TMI de violência (Figura 2b). Esta última taxa também apresentou aglomerados alto-alto em parte da mesorregião do agreste potiguar (Figura 2b). Este tipo de aglomerado foi evidenciado na mesorregião do central potiguar para a renda média domiciliar (Figura 2c). Já para a taxa de desemprego o aglomerado alto-alto concentra-se em parte da região central e oeste potiguar (Figura 2d).

No MoranMap é possível verificar todos os polígonos com significativo índice de autocorrelação espacial, onde neste estudo pode-se observar que os município da mesorregião leste potiguar, como Natal e outros que compõem a Região Metropolitana da capital, como Extremoz, e Parnamirim apresentaram significância de aglomerados do tipo alto-alto relativos tanto a TMI de ZIKV no biênio de 2015-2016 quanto para TMI de violência e renda média domiciliar, porém não se destacou na taxa de desemprego (Figura 3). É possível verificar ainda, para renda média domiciliar, um aglomerado do tipo alto -alto para municípios da mesorregião central potiguar, mais especificamente os da microrregião do Seridó Oriental (Figura 3c).

Quando da análise bivariada espacial (LISA), os municípios de Extremoz, Natal e São Gonçalo emergiram como aglomerados com alta TMI de ZIKV no biênio 2015-2016 e alta TMI de violência (Figura 4a). Em Extremoz e Natal também se encontrou uma alta TMI de ZIKV no biênio 2015-2016 e alta renda média domiciliar. Este 


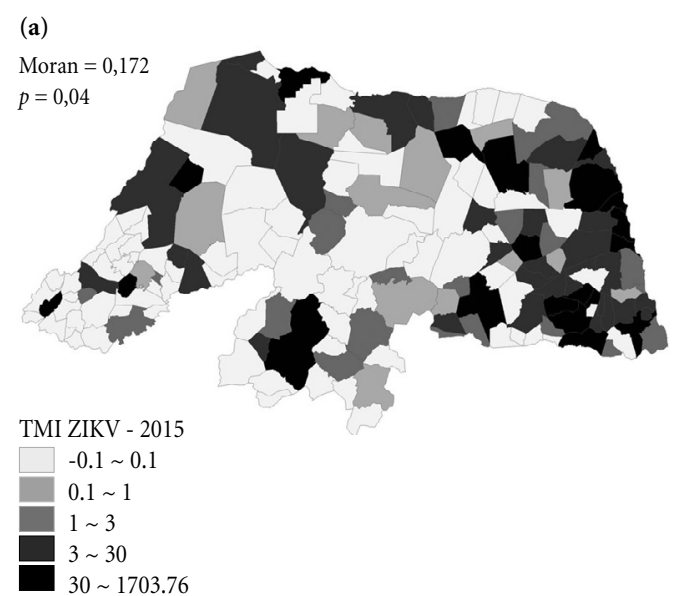

(c)

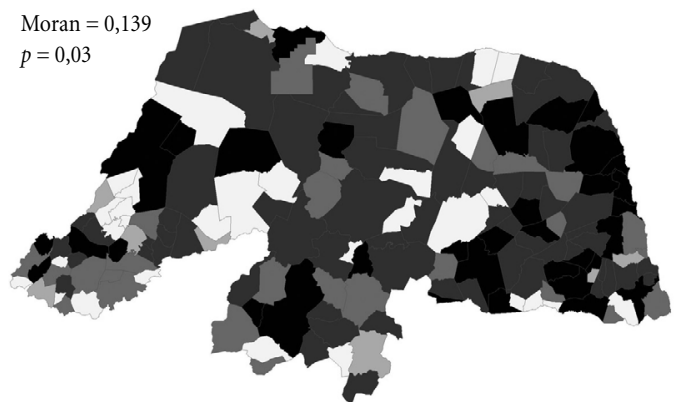

(b)

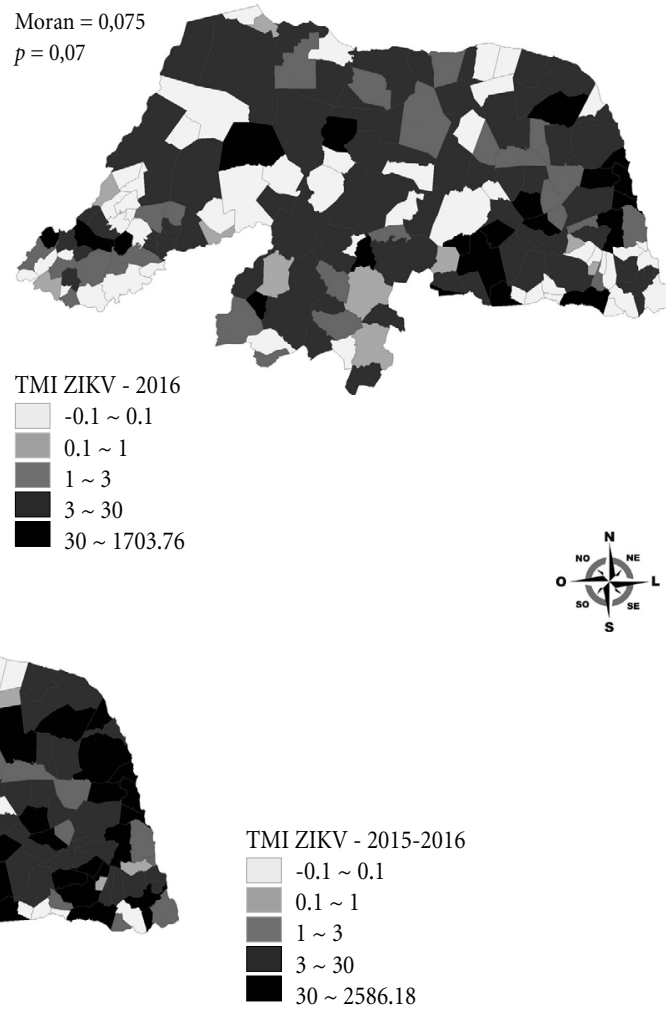

Figura 1. (a) Mapa temático da TMI de ZIKV em 2015; (b) Mapa temático da TMI de ZIKV em 2016; (c) Mapa temático da TMI de ZIKV no biênio 2015-2016 com o respectivo valor de Moran Global e sua significância estatística. Estado do Rio Grande do Norte, Brasil. Santa Cruz, 2019.

último achado também foi evidenciado para o município de Parnamirim (Figura 4b).

Ademais, observou-se formação de aglomerados de altas TMI de ZIKV no biênio 2015-2016 e baixa taxa de desemprego nos municípios de Serrinha, Caicó e Timbaúba dos Batistas (Figura 4c).

Na regressão linear múltipla, para verificar se a TMI de violência, a renda média domiciliar e a taxa de desemprego seriam capazes de prever a TMI de ZIKV verificou-se que a TMI de violência e Renda média domiciliar são capazes de explicar 55\% da variação da TMI de ZIKV ( $\mathrm{R}^{2}$ ajustado $=0,55)$. Esta análise resultou em um modelo estatisticamente significativo $[\mathrm{F}(1,164)$ $=102,37 ; p=<0,001 ; \mathrm{R}^{2}$ ajustado $\left.=0,550\right]$, demonstrando que a TMI de violência $(\beta=0,609$, $\mathrm{t}=9,402, p=<0,001)$ e Renda média domiciliar $(\beta=0,200, t=3,093, p=0,002)$ são previsores $d a$ TMI de ZIKV (Tabela 1).

\section{Discussão}

No presente estudo foi possível observar que a TMI para o ZIKV no biênio 2015-2016 obedeceu a um padrão geográfico de distribuição espacial no território do RN, com formação de aglomerados alto-alto para TMI de violência e renda domiciliar principalmente na Região Metropolitana de Natal. A formação de aglomerados com taxa de desemprego se apresentou difusa no território e essa situação foi evidenciada mais uma vez na análise de regressão múltipla, onde a variável não se mostrou como preditora para TMI de ZIKV.

Estes achados corroboram sobre a importância dos indicadores de desigualdades sociais para o entendimento do processo saúde-doença de uma população ${ }^{7,9,20,21}$. Pesquisas já apontam correlação entre determinantes sociais de saúde como etnia, escolaridade, renda e ZIKV e suas consequências, a exemplo da microcefalia ${ }^{9-11}$. 

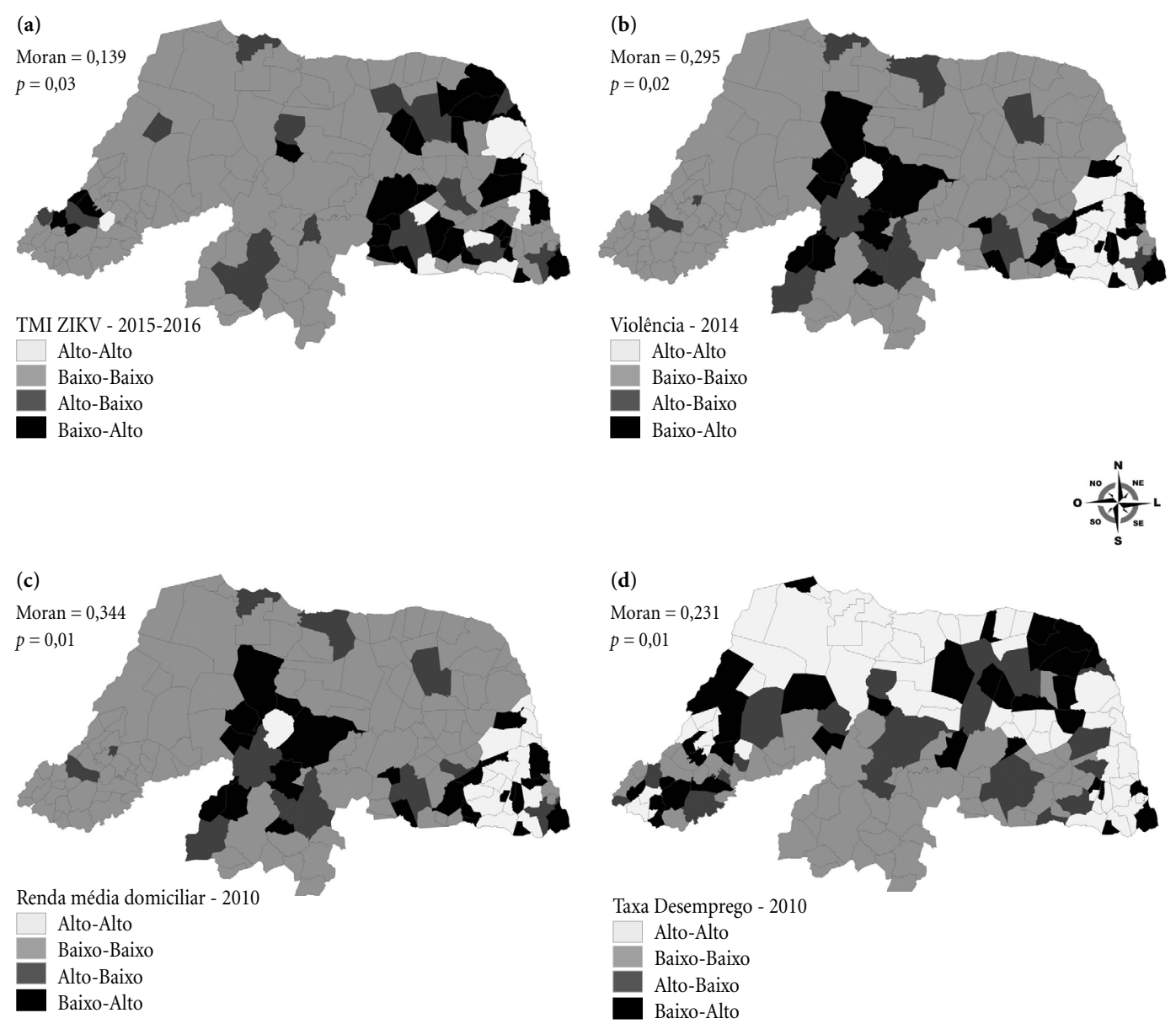

Figura 2. (a) Mapa da autocorrelação espacial BoxMap da TMI de ZIKV no biênio 2015-2016; (b) Mapa da autocorrelação espacial BoxMap da TMI de Violência em 2014; (c) Mapa da autocorrelação espacial BoxMap da Renda Média Domiciliar em 2010; (d) Mapa da autocorrelação espacial BoxMap da Taxa de Desemprego. Estado do Rio Grande do Norte, Brasil. Santa Cruz, 2019.

Vale destacar, que em menos de um ano após sua introdução no país, o vírus ZIKV se distribuiu desigualmente por todas as regiões do Brasil, concentrando maior número de casos nas regiões Nordeste e Sudeste e posteriormente passou a exibir transmissão continuada em grande parte do território brasileiro $9,11,20,22$.

Garcia $^{20}$ aponta dentre os determinantes da evolução do ZIKV as dificuldades no controle vetorial, deficiências nas ações voltadas ao planejamento familiar, bem como falhas na atenção materno-infantil, aliadas às marcantes desigualdades que caracterizam o país, contribuindo para que a febre pelo ZIKV e sua consequência mais devastadora - a microcefalia em bebês - se tornassem males endêmicos que atingem princi- palmente famílias de baixa renda, residentes nas regiões menos desenvolvidas.

A relação entre renda média domiciliar com a TMI de ZIKV no biênio 2015-2016, já foi indicada por outros estudos que encontraram baixas condições socioeconômicas associadas ao aumento da incidência de ZIKV e de suas comorbidades a exemplo da microcefalia. Esses estudos ressaltam que más condições socioeconômicas podem comprometer o desenvolvimento fetal, seja por ocasionar acesso restrito aos serviços de saúde e vulnerabilidade social, seja pela dificuldade da mãe em compreender as reais necessidades do seu bebêt $\hat{e}^{1,21,23}$.

Estudos ressaltam a importância de não negligenciar a influência dos determinantes sociais, 

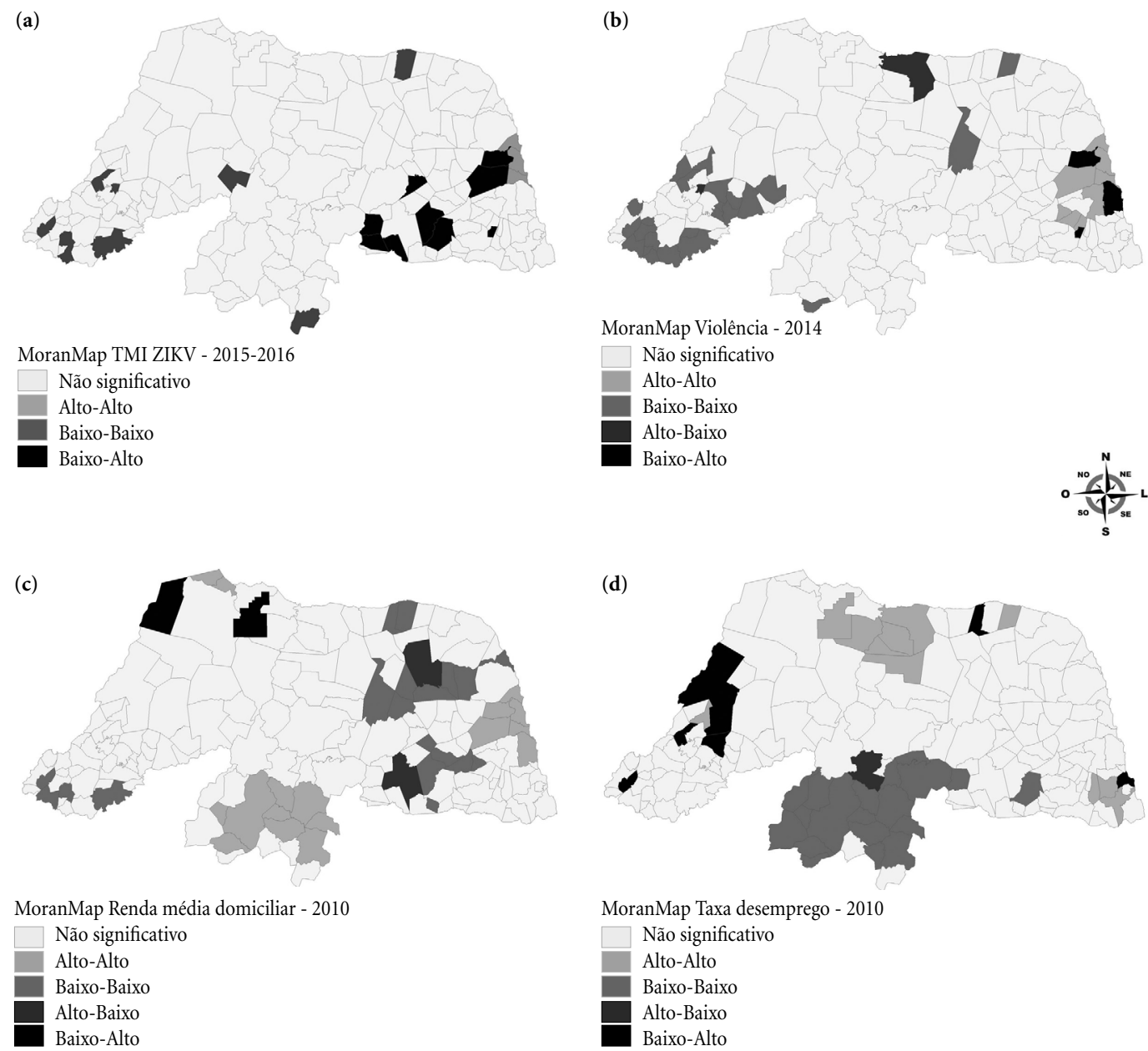

Figura 3. (a) Mapa da autocorrelação espacial MoranMap da TMI de ZIKV no biênio 2015-2016; (b) Mapa da autocorrelação espacial MoranMap da TMI de Violência em 2014; (c) Mapa da autocorrelação espacial MoranMap da Renda Média Domiciliar em 2010; (d) Mapa da autocorrelação espacial MoranMap da Taxa de Desemprego. Estado do Rio Grande do Norte, Brasil. Santa Cruz, 2019.

econômicos e ambientais que estejam relacionados ao ZIKV, uma vez que conhecer o perfil e a causa das doenças de um território torna-se fundamental para subsidiar o planejamento de políticas públicas de saúde e fortalecimento do Sistema Ûnico de Saúde (SUS) o que poderia, para a região apontada nesse estudo, reduzir os agravos e a modificação do cenário territorial ${ }^{7,24,25}$.

Possivelmente um dos fatores que tenha corroborado para a existência de uma correlação entre alta TMI de ZIKV no biênio de 2015-2016 com alta renda média domiciliar seja o fato de que esses municípios com melhor renda (capitais e região metropolitana) sejam os que possuem melhor notificação de casos, característica esta também observada por Ishitani et al. ${ }^{26}$ que justifica esta relação com melhores condições técnico-operacionais do sistema de vigilância epidemiológica para detectar, notificar e investigar os $\operatorname{casos}^{27,28}$.

Estas condições técnico-operacionais podem justificar outro dado de nosso estudo que foi o aglomerado de altas taxas de violência com alta TMI de ZIKV da região correspondente à mesorregião leste potiguar a qual abrange a Região Metropolitana de Natal, capital do estado, exatamente com serviços de saúde mais sensíveis na deteç̧ão e notificação dos casos.

Pesquisas sugerem que a ocorrência da violência esteja associada a fatores socioambientais 
a) Clústers bivariada LISA entre TMI ZIKV no biênio 20152016 e TMI de Violência em 2014.

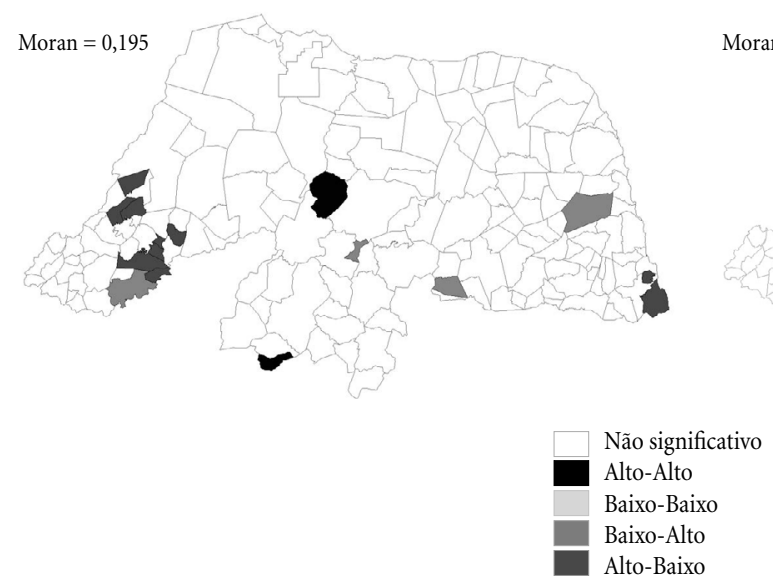

b) Clústers bivariada LISA entre TMI ZIKV no biênio 20152016 e Renda Média Domiciliar em 2010.

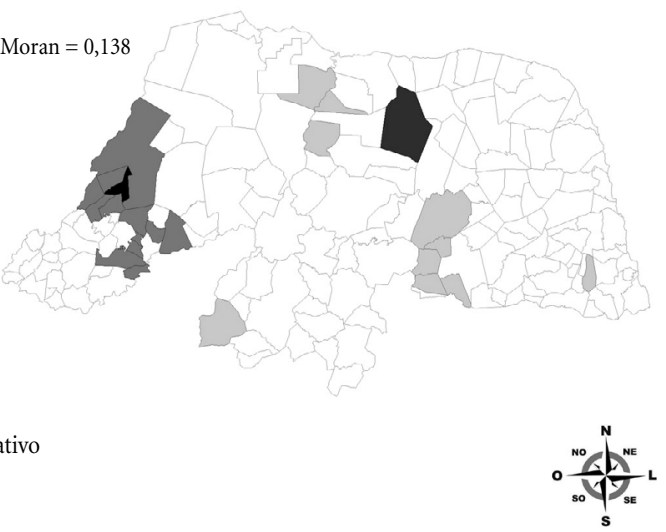

c) Clústers bivariada LISA entre TMI ZIKV no biênio 2015-2016 e Taxa de Desemprego em 2010.

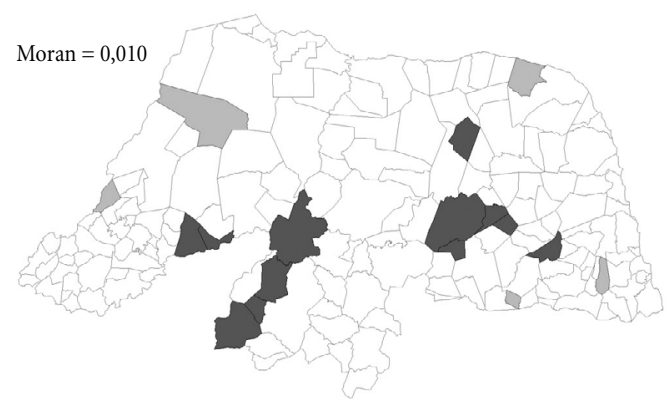

Figura 4. Correlação espacial entre da Taxa Média de Incidência de ZIKV no biênio 2015-2016 com: (a) Incidência de Violência em 2010; (b) Renda Média Domiciliar per capta 2010; e (c) Taxa de Desemprego em 2010. Estado do Rio Grande do Norte, Brasil, 2019.

Tabela 1. Modelo de regressão linear múltipla com os preditores da variável dependente Taxa Média de Incidência de ZIKV no biênio 2015-2016.

\begin{tabular}{|c|c|c|c|c|c|}
\hline & \multicolumn{2}{|c|}{ Coeficiente não padronizado } & \multirow{2}{*}{$\begin{array}{c}\begin{array}{c}\text { Coeficiente } \\
\text { padronizado }\end{array} \\
\text { Beta }\end{array}$} & \multirow{2}{*}{$\mathbf{t}$} & \multirow{2}{*}{$\mathbf{p}$} \\
\hline & B & Erro padrão & & & \\
\hline (Constante) & $-152,656$ & 50,233 & & $-3,039$ & 0,003 \\
\hline Incidência de violência em 2014 & 5,644 & 0,600 & 0,609 & 9,402 & 0,000 \\
\hline Renda Média Domiciliar em 2010 & 0,529 & 0,171 & 0,200 & 3,093 & 0,002 \\
\hline
\end{tabular}

como concentração populacional elevada, desigualdade na distribuição de riquezas, iniquidades na saúde, baixa renda familiar entre outras situações, e que esses fatores configuram em desigualdades sociais de acesso ao consumo de bens essenciais a vida como acesso aos serviços de saúde ${ }^{29-32}$.

De acordo com Ferri et al. ${ }^{33}$ a violência está associada com distúrbios ao longo da vida e, quando ocorre durante a gestação, associa-se a 
desfechos neonatais negativos. A incidência de violência é um problema de saúde pública com repercussões na saúde individual e coletiva, exigindo a formulação de práticas e de serviços específicos. Este fato ganha ainda mais visibilidade diante das estatísticas de incidência de violência que classificam o RN como líder no ranking dos estados nordestinos com uma taxa de 53,4 homicídios por 100 mil habitantes no ano de 2016, e reforça a importância de investimentos em uma arquitetura institucional que capacite os estados a lhe assegurar ferramentas de governança afim de que efetivamente sejam implantadas políticas de pacificação ${ }^{34-36}$.

Entretanto, uma das limitações deste estudo foi não georeferenciar informações utilizando níveis geográficos mais detalhados (estudos com pontos, bairros, setores censitários) que pudessem verificar a existência de áreas nesses municípios de vulnerabilidade distintas em decorrência dos efeitos de escala e de agregação de áreas. Ademais, os coeficientes de correlação podem ser diferentes daqueles em nível individual, podendo ocasionar o que se chama de "falácia ecológica" 37 .

Outra limitação incorre sob uma das desvantagens de se trabalhar com banco de dados secundários que é a data de coleta. Para as variáveis independentes não se obteve na base de dados do DATASUS e IBGE dados atualizados para o mesmo período do surto de ZIKV. Ressalta-se, no entanto, que foram coletados os dados disponíveis que correspondesse ao período mais próximo ao de análise de incidência de ZIKV analisada neste estudo. De acordo com Freitas et al. ${ }^{38}$, essa limitação decorre destas variáveis serem oriundas dos censos demográficos, o que gera uma descontinuidade dos dados de base, uma vez que são realizados em média a cada dez anos.

Ademais, apesar de apresentar um delineamento de correlações ecológicas, as contribui- ções desta pesquisa certamente oferecerão subsídios gerados para políticas públicas com ênfase nas ações preventivas, que poderão ser usadas como critério para repartição mais equânime dos recursos públicos, priorizando as regiões que apresentam as piores características de desigualdade social em saúde.

\section{Conclusão}

Este estudo demonstrou que municípios da mesorregião do leste potiguar, como a capital Natal e sua região metropolitana, com mais notificações de violência e renda média favorável, detêm maiores TMI de casos de ZIKV, fenômeno mediado possivelmente pela existência de melhor acesso aos serviços de saúde, fato que melhora a notificação dos casos de ZIKV nesses municípios.

Esses achados podem ainda refletir a densidade demográfica destes municípios, uma vez que alta densidade populacional pode conferir maior clareza aos problemas socioambientais.

Os achados deste estudo indicam a existência da correlação entre os determinantes socioambientais e casos de ZIKV presente no estado do $\mathrm{RN}$, e que poderão subsidiar novas discussões em torno desta temática, a qual atualmente tem se destacado pela sua repercussão e danos ocasionados, evidenciando que se deve compreender não somente o ciclo de vida e de transmissão do ZIKV.

Além disso, reconhece-se ainda a importância dos Sistemas de Informação em Saúde para a Vigilância Epidemiológica na análise das desigualdades sociais em saúde sob a premissa de que esse conhecimento é fundamental na fomentação de estratégias de planejamento e gestão em saúde para o enfrentamento desta enfermidade e de suas consequências.

\section{Colaboradores}

LS Cunha, WR Medeiros, FAV Lima Junior, SA Pereira participaram ativamente da construção deste artigo, desde a elaboração dos resultados, escrita e revisão do texto. 


\section{Referências}

1. Lopes N, Nozawa C, Linhares REC. Características gerais e epidemiologia dos arbovírus emergentes no Brasil. Rev Pan-Amazônica Saude 2014; 5(3):55-64.

2. Brasil. Ministério da Saúde (MS). Secretaria de Vigilância em Saúde. Coordenação-Geral de Desenvolvimento da Epidemiologia em Serviços. Guia de Vigilância em Saúde. Volume Único. Brasília: MS; 2019.

3. Zanluca C, Melo VCA, Mosimann ALP, Santos GIV, Santos CND, Luz K. First report of autochthonous transmission of Zika virus in Brazil. Memórias Instituto Oswaldo Cruz 2015; 110(4):569-572.

4. Lima-Camara TN. Arboviroses emergentes e novos desafios para a saúde pública no Brasil. Rev Saúde Pública 2016; 50:36.

5. Governo do Estado do Rio Grande do Norte. Secretaria de Estado da Saúde Pública (SESAP). SESAP monitora casos de Zika vírus no Estado [página na Internet]. 2015. Disponível em: http://www.parquedasdunas.rn.gov.br/Conteudo.asp?TRAN=ITEM\&TAR $\mathrm{G}=76613 \& \mathrm{ACT}=$ null\&PAGE $=$ null\&PARM $=$ null\&L$\mathrm{BL}=\mathrm{NOT} \% \mathrm{C} 3 \% 8 \mathrm{DCIA}$

6. Brasil. Ministério da Saúde (MS). Secretaria de Vigilância em Saúde. Monitoramento dos casos de dengue, febre de chikungunya e febre pelo vírus Zika, até a Semana Epidemiológica 52, 2016 [documento na Internet]. Boletim Epidemiológico 2017; 48(3):1-11. Disponível em: https://portalarquivos2.saude.gov. br/images/pdf/2017/abril/06/2017-002-Monitoramento-dos-casos-de-dengue--febre-de-chikungunya-e-febre-pelo-v--rus-Zika-ate-a-Semana-Epidemiologica-52--2016.pdf

7. Nunes J, Pimenta DN. A epidemia de Zika e os limites da saúde global. Lua Nova 2016; 98:21-46.

8. Menezes SA, Costa YA, Costa HP, Gildo MGP, Sampaio MGV. Arboviroses: O Impacto da Febre Zika na Sociedade. Rev Expressão Católica Saude 2016; 1(1):25-32.

9. Butler D. Brazil's birth-defects puzzle: Zika virus might not be only factor in reported microcephaly surge. Nature 2016; 535(7613):475-477.

10. Araújo TVB, Ximenes RAA, Miranda-Filho DB, Souza WV, Montarroyos UR, Melo APL, Valongueiro S, Albuquerque MFPM, Braga C, Filho SPB, Cordeiro MT, Vazquez E, Cruz DDCS, Henriques CMP, Bezerra LCA, Castanha PMDS, Dhalia R, Marques-Júnior ETA, Martelli CMT, Rodrigues LC, Investigators from the Microcephaly Epidemic Research Group, Brazilian Ministry of Health, Pan American Health Organization, Instituto de Medicina Integral Professor Fernando Figueira, State Health Department of Pernambuco. Association between microcephaly, Zika virus infection, and other risk factors in Brazil: final report of a case-control study. Lancet Infect Dis 2018; 18(3):328-336.

11. Marinho F, Araújo VEM, Porto DL, Ferreira HL, Coelho MRS, Lecca RCR, Oliveira H, Poncioni IPA, Maranhão MHN, Mendes YMMB, Fernandes RM, Lima RB, Rabello Neto DL. Microcefalia no Brasil: prevalência e caracterização dos casos a partir do Sistema de Informações sobre Nascidos Vivos (Sinasc), 2000-2015. Epidemiol Serv Saude 2016; 25(4):701-712.
12. Barreto ML. Desigualdades em Saúde: uma perspectiva global. Cien Saude Colet 2017; 22(7):2097-2108.

13. Travassos C, Oliveira EXG, Viacava F. Desigualdades geográficas e sociais no acesso aos serviços de saúde no Brasil: 1998 e 2003. Cien Saude Colet 2006; 11(4):975-986.

14. Rochlin I, Ninivaggi DV, Hutchinson ML, Farajollahi A. Climate Change and Range Expansion of the Asian Tiger Mosquito (Aedes albopictus) in Northeastern USA: Implications for Public Health Practitioners. PLoS ONE 2013; 8:e60874.

15. Almeida CAP, Silva RM. Análise da ocorrência dos casos de dengue e sua relação com as condições socioambientais em espaços urbanos: os casos de João Pessoa, Cabedelo e Bayeux, no estado da Paraíba-Brasil. Hygeia 2018; 14(27):56-79.

16. Gottschalg MFS. Segregação Sócio-Espacial Urbana e Intervenção Estatal: Uma abordagem geográfico-social. Belo Horizonte: CRESS; 2012.

17. Sant'anna CF, Cezar-Vaz MR, Cardoso LS, Erdmann AL, Soares JFS. Determinantes Sociais de Saúde: características da comunidade e trabalho das enfermeiras na saúde da família. Rev Gaúcha Enferm 2010; 31(1):92-99.

18. Buss PM, Pellegrini Filho A. A saúde e seus determinantes sociais. Physis 2007; 17(1):77-93.

19. Brasil. Instituto Brasileiro de Geografia e Estatística (IBGE). Censo Populacional 2010 [página na Internet]. 2010. Disponível em: https://censo2010.ibge.gov.br/

20. Garcia LP. Epidemia do vírus Zika e microcefalia no Brasil: Emergência, evolução e enfrentamento. Brasília: IPEA; 2018. (Texto para Discussão 2368).

21. Fontoura FC, Cardoso MVLML. Association between congenital malformation and neonatal and maternal variables in neonatal units of a Northeast Brazilian city. Texto Contexto Enferm 2014; 23(4):907-914.

22. Brasil. Ministério da Saúde (MS). Secretaria de Vigilância em Saúde. Situação epidemiológica da infecção pelo vírus Zika no Brasil, de 2015 a 2017 [página na Internet]. Boletim Epidemiológico 2018; 49(47):1-10. Disponível em: https://www.saude.gov.br/images/ pdf/2018/novembro/12/2018-034.pdf

23. Abreu TT, Novais MCM, Guimarães ICB. Crianças com microcefalia associada a infecção congênita pelo vírus Zika: características clínicas e epidemiológicas num hospital terciário. Rev Cien Med Biol 2016; 15(3):426-433.

24. Moraes $\mathrm{CH}$, Loose EB, Girardi IMT. Dengue, Zika e Chikungunya: Análise da cobertura do risco de doenças associadas às mudanças climáticas sob a ótica do Jornalismo Ambiental. Disertaciones: Anuario Electrónico Estudios Comunicación Social 2017; 10(2):16.

25. Almeida LS, Cota ALS, Rodrigues DF. Saneamento, Arboviroses e Determinantes Ambientais: Impactos na saúde urbana. Cien Saude Colet [periódico na Internet]. 2019. Disponível em: http://www. cienciaesaudecoletiva.com.br/artigos/saneamento-arboviroses-e-determinantes-ambientais-impactos-na-saude-urbana/17113

26. Ishitani LH, Franco GC, Perpétuo IHO, França E. Desigualdade social e mortalidade precoce por doenças cardiovasculares no Brasil. Rev Saude Publica 2006; 40(4):684-691. 
27. Assis VC, Amaral MPH, Mendonça AE. Análise da qualidade das notificações de dengue informadas no sistema de informação de agravos de notificação, na epidemia de 2010, em uma cidade pólo da zona da mata do estado de Minas Gerais. Rev APS 2014; 17(4):429-437.

28. Fernandes LA, Gomes MMF. Análise dos dados do SINAN sobre dengue nos municípios da Área Metropolitana de Brasília (AMB)/Analysis of SINAN data on dengue in the municipalities of the Metropolitan Area of Brasília (AMB). Braz J Health Rev 2018; 1(2):314-322.

29. Cardia N, Schiffer S. Violência e desigualdade social. Cien Cultura 2002; 54(1):25-31.

30. Macedo AC, Paim JS, Silva LMV, Costa MCN. Violência e desigualdade social: mortalidade por homicídios e condições de vida em Salvador, Brasil. Rev Saude Publica 2001; 35(6):515-522.

31. Resende JP, Andrade MV. Crime social, castigo social: desigualdade de renda e taxas de criminalidade nos grandes municípios brasileiros. Estudos Econom 2011; 41(1):173-195.

32. Morais IRD, Valentim RAM, Costa SM. Produção do espaço urbano e políticas públicas: a operacionalização do observatório do aedes aegypti no Rio Grande do Norte/RN. Hygeia 2018; 14(30):17-28.

33. Ferri CP, Mitsuhiro SS, Barros MCM, Chalem E, Guinsburg R, Patel V, Prince M, Laranjeira R. The impact of maternal experience of violence and common mental disorders on neonatal outcomes: a survey of adolescent mothers in Sao Paulo, Brazil. BMC Public Health 2007; 7(1):209.

34. Instituto de Pesquisa Econômica Aplicada (IPEA). Fórum Brasileiro de Segurança Pública (FBSP). Atlas da violência. Rio de Janeiro: IPEA; 2018.

35. Mello Jorge MHP, Koizumi MS, Tono VL. Causas Externas: O que são, como afetam o setor saúde, sua medida e alguns subsídios para a sua prevenção. Rev Saude-UNG-Ser 2007; 1(1):37-47.

36. Dahlberg LL, Krug EG. Violência: um problema global de saúde pública. Cien Saude Colet 2006; 11(Sup.):1163-1178

37. Câmara G, Carvalho MS, Cruz OG, Correia V. Análise Espacial de Áreas. In: Druck S, Carvalho MS, Câmara G, Monteiro AVM, editores. Análise Espacial de Dados Geográficos. Brasília: EMBRAPA; 2004.

38. Freitas RMS, Smiderle JJ, Dias SA, Souza RM, Zidde C. Medindo o saneamento: potencialidades e limitações dos bancos de dados brasileiros. FGV CERI; 2018. 
